\title{
Endocarditis trombótica no bacteriana como manifestación inicial de neoplasia pulmonar
}

\author{
P. HERRERA DE PABLO, E. ESTEBAN ESTEBAN ${ }^{1}$, J. V. GIMÉNEZ SOLER, \\ A. PAREJA MARTÍNEZ, J. MOSCOSO DEL PRADO
}

Servicio de Medicina Interna. 'Servicio de Cardiología. Hospital Arnau de Vilanova. Valencia

\begin{abstract}
RESUMEN
La endocarditis trombótica no bacteriana (ETNB) es una causa poco frecuente de embolismo sistémico cuya presencia suele asociarse a enfermedades malignas y estados de hipercoagulabilidad. La ecocardiografía constituye una técnica útil para el diagnóstico. Sin embargo las lesiones valvulares de la ETNB son ecográficamente indistinguibles de las vegetaciones observadas en la endocarditis infecciosa (EI), por lo cual es necesario establecer un diagnóstico diferencial con esta entidad. El tratamiento de la endocarditis trombótica es controvertido coincidiendo la literatura en el uso de heparina intravenosa. Presentamos el caso de una paciente de 42 años de edad con infartos isquémicos cerebrales múltiples, en la cual la realización una ecocardiografía transesofágica (ETE) ayudó a establecer el diagnóstico de ETNB. La etiología infecciosa fue descartada tras practicar un estudio microbiológico exhaustivo. En la búsqueda de patologías causantes o relacionadas con la ETNB se encontró la presencia de un adenocarcinoma pulmonar como enfermedad subyacente.
\end{abstract}

PALABRAS CLAVE: Endocarditis trombótica no bacteriana. Ecocardiografía. Cáncer.
NONBACTERIAL THROMBOTIC ENDOCARDITIS AS INITAL EVENT OF LUNG CANCER

Herrera de Pablo P, Esteban Esteban E, Giménez Soler JV, Pareja Martínez A, Moscoso del Prado J. Endocarditis trombótica no bacteriana como manifestación inicial de neoplasia pulmonar. An Med Interna (Madrid) 2004; 21: 495-497.

\section{INTRODUCCIÓN}

La ETNB fue descrita por primera vez por Ziegler en 1888 con el término tromboendocarditis. Desde entonces esta afección ha recibido diversas denominaciones tales como endocarditis marántica, endocarditis verrucosa atípica o endocarditis de Libman Sacks. En todos los casos aparece como hallazgo común un trombo estéril adherido al endocardio valvular cuya presencia se relaciona con la aparición de eventos embólicos (1). Este proceso ha sido identificado en el contexto de numerosas situaciones patológicas asociadas a estados de hipercoagulabilidad, pudiendo aparecer en pacientes con neoplasias malignas, enfermedades mieloproliferativas, como complicación de una sepsis, en quemaduras graves, en pacientes con síndrome antifosfolípido primario o asociado a lupus eritematoso sistémico, en el síndrome de inmunodeficiencia adquirida (1-6) y en enfermedades pulmonares que cursan con hipoxia (7).

La ETNB asociada a neoplasia suele ocurrir en pacientes con cáncer diseminado, resultando infrecuente que su diagnóstico preceda al de la enfermedad maligna (2). Presentamos el caso de una paciente con infartos isquémicos cerebrales múltiples que fue diagnosticada de ETNB. El estudio posterior de la paciente mostró la existencia de una neoplasia pulmonar como enfermedad asociada.

\section{CASO APORTADO}

Mujer de 42 años, fumadora de 20 cigarrillos día, en tratamiento con anticonceptivos orales durante los últimos 5 años, sin otros factores de riesgo cardiovascular y con antecedentes familiares de padre 
fallecido por neoplasia ósea y madre en tratamiento por cáncer de mama. La paciente consulta por apreciar desde hacía 15 días torpeza para la ejecución de actos finos con la mano derecha y dolor en dicha extremidad. En el momento del ingreso se encontraba apirética y con tensión arterial normal. En la exploración neurológica se apreció a una paciente consciente y orientada, con respuestas lentas. Había una ligera paresia braquial derecha de predominio distal sin trastorno sensitivo evidente y una dismetría derecha puesta de manifiesto en la prueba dedo-nariz. El resto del examen neurológico fue normal. En la exploración general destacaba la existencia lesiones purpúricas en plantas de pies, pulpejos de los dedos y hemorragias en astilla en uñas de manos. La auscultación cardíaca y el resto de exploración fue normal.

En el hemograma se apreció una cifra de hemoglobina de 11,7 $\mathrm{g} / \mathrm{dl}$ y un hematocrito de $33,7 \%$ con índices normales. Las series blanca y plaquetar fueron normales. La VSG fue de $31 \mathrm{~mm} / \mathrm{h}$. La $\mathrm{LDH}$ fue de $1.238 \mathrm{U} / \mathrm{l}$. El resto de las principales determinaciones bioquímicas incluyendo hormonas tiroideas, anticuerpos antinucleares y Anti-DNA, anticuerpos anticardiolipina, anticoagulante lúpico, $\mathrm{C} 3$ y $\mathrm{C} 4$ y crioglobulinas fueron normales o negativas. El estudio básico de coagulación y el estudio completo de trombofilia fueron también normales. El electrocardiograma mostró ritmo sinusal, sin alteraciones. En la radiografía de tórax se observó un nódulo de 1.5 $\mathrm{cm}$ en lóbulo superior derecho. La tomografía axial computerizada (TAC) de tórax confirmó el nódulo y pequeñas adenopatias paratraqueales. La TAC abdominal detectó dos infartos isquémicos esplénicos. En la resonancia magnética (RM) cerebral se apreciaron varias lesiones hiperintensas en la secuencia potenciada en T2 en la cortical de las circunvoluciones frontal izquierda, parieto-occipital izquierda y derecha y en cerebelo, sin edema significativo y sin efecto masa.

La presencia de múltiples embolismos en diferentes territorios hizo sospechar una fuente común de origen cardíaco, por lo cual se practicó un estudio ecocardiográfico. La ecocardiografía transtorácica (ETT) mostró cavidades cardíacas de dimensiones y motilidad normal, con una insuficiencia mitral de grado ligero, siendo el resto de exploración normal. Posteriormente la ETE puso de manifiesto la presencia de dos pequeñas masas redondeadas de 2 x $3 \mathrm{~mm}$, adheridas al extremo libre de la superficie auricular de la válvula mitral (Fig. 1). Inicialmente se planteó el diagnóstico diferencial de endocarditis infecciosa (EI) versus ETNB, instaurándose tratamiento con antibioterapia empírica y heparina sódica intravenosa. Los hemocultivos seriados tanto en medios habituales como especiales para descartar infecciones por microrganismos exigentes (grupo HACEK, especies de Brucella, de Neisseria, anaerobios, corinebacterias, Legionella y hongos) fueron negativos. La serología luética, VIH, VHB, VHC, Legionella, Chlamydia, Mycoplasma, Borrelia, Brucella, Rickettsia y Coxiella fase I y II, y la PCR para Bartonella y Tropheryma whippelii fueron negativas. El estudio citobioquímico y los principales estudios microbiológicos del líquido cefalorraquídeo fueron normales o negativos.

Para completar el estudio de la masa pulmonar se realizó una tomografía por emisión de positrones (PET), que detectó un foco hipermetabólico en lóbulo superior derecho, varios nódulos hipermetabólicos compatibles con afectación adenopática, así como un aumento de actividad en lóbulo tiroideo derecho (Fig. 2). El estudio anatomo-patológico de los nódulos pulmonar y tiroideo mostraron la existencia de un adenocarcinoma de pulmón. Se descartó la indicación de quimioterapia manteniéndo la anticoagulación, sin embargo, la evolución clínica fue desfavorable apreciándose en las exploraciones de neuroimagen (TAC y RM) un aumento en el número y tamaño de las lesiones cerebrales. Tres meses después del ingreso la paciente falleció.

\section{DISCUSIÓN}

La ETNB es una entidad caracterizada por la presencia de vegetaciones de origen no infeccioso constituidas por acúmu-

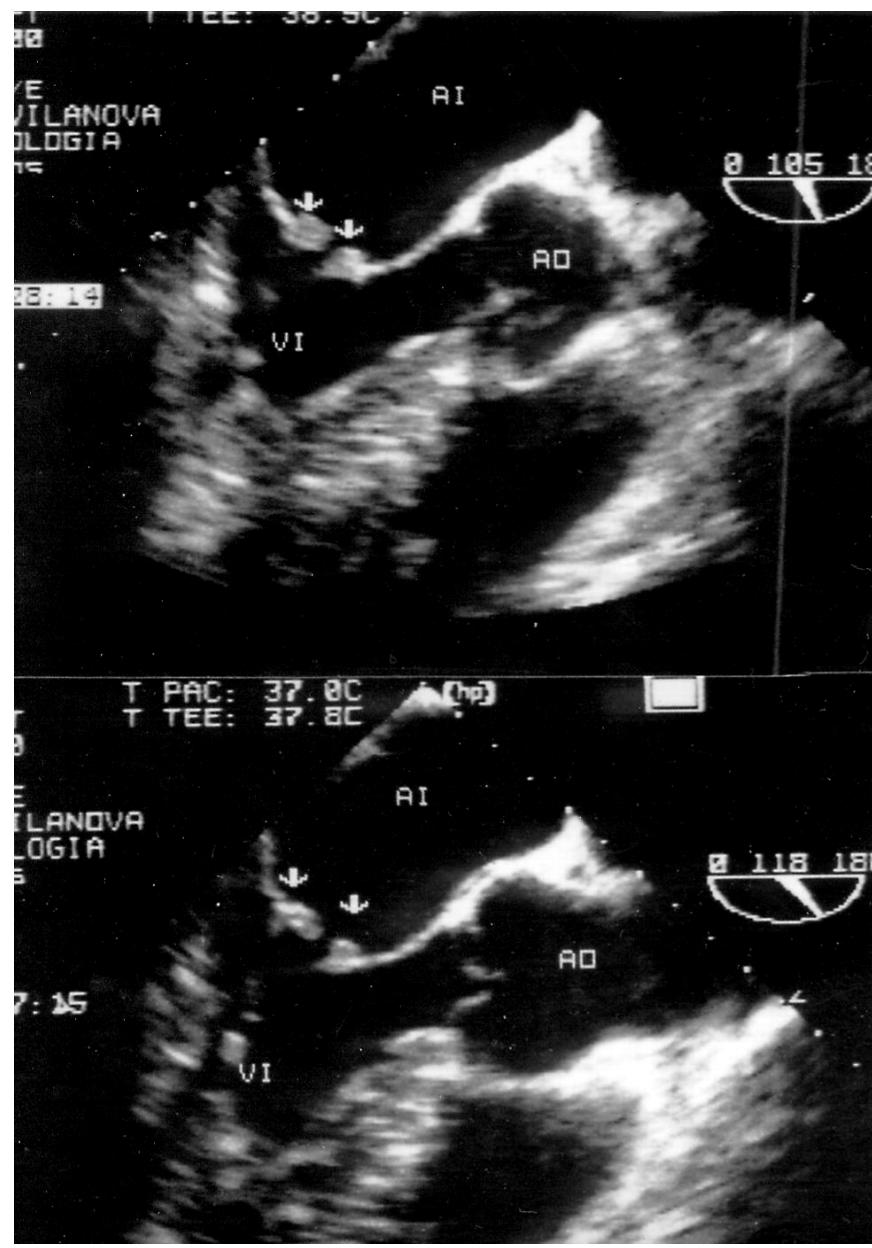

Fig. 1. Ecocardiografia Transesofágica; Planos medioesofágicos en los que se observan dos pequeñas masas adheridas al extremo libre de la superficie auricular de la vávula mitral; Al: aurícula izquierda; VI: ventrículo izquierdo; AO: Aorta.

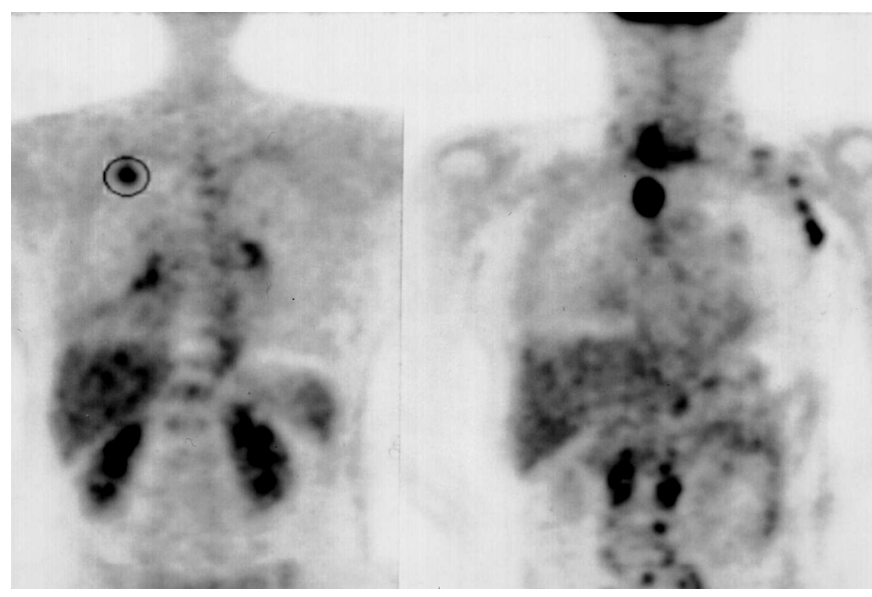

Fig. 2. PET; Derecha: se observa foco hipermetabólico situado en lóbulo pulmonar superior derecho; Izquierda: nódulo hipermetabólico en región paratraqueal derecha y marcada actividad hipermetabólica en lóbulo derecho tiroideo.

los de fibrina y plaquetas con alto potencial embolígeno. Este proceso ha sido descrito en numerosas situaciones clínicas, siendo las más frecuentes las enfermedades neoplásicas, sobre todo en su fase terminal (1). Habitualmente, el diagnóstico de 
ETNB asociado a neoplasia se realiza en pacientes con enfermedad diseminada conocida, resultando poco habitual que el diagnóstico de endocarditis preceda al de enfermedad maligna. Así, Roger et al, en una serie de 42 pacientes con cáncer e infarto cerebral relacionado con ETNB encuentran que sólo en 2 casos el cuadro neurológico precedió al diagnóstico de malignidad (2).

La prevalencia postmortem de ETNB en pacientes fallecidos por cáncer es superior al 1,3\% (8-9) Sin embargo datos recientes procedentes de estudios ecocardiográficos indican que esta prevalencia ha sido infraestimada. Edoute et al, en una serie de 200 pacientes oncológicos estudiados de forma prospectiva mediante ecocardiografía, encuentran lesiones valvulares compatibles con ETNB en un $19 \%$ de los casos. Estas lesiones fueron especialmente frecuentes entre los pacientes con cáncer de páncreas, pulmón y linfoma (4).

Aunque la patogénesis exacta de estas lesiones no se conoce, la mayoría de los autores están de acuerdo en que la existencia de un daño valvular previo, sumado a una alteración de los mecanismos de coagulación puede conducir al depósito de plaquetas y agregados de fibrina sobre el endotelio vascular (1). En el caso de los pacientes oncológicos, la lesión endotelial inicial podría estar causada por sustancias segregadas por el propio tumor tales como el factor de necrosis tumoral o la interleucina 1 (10).

El embolismo y la disfunción valvular son las dos complicaciones más frecuentes encontradas en la ETNB. La incidencia de embolias sistémicas es del 50\%, siendo las manifestaciones neurológicas las más comunes (1); de hecho, entre los pacientes con cáncer el $25 \%$ de los ictus son causados por embolización de vegetaciones asépticas (11). A diferencia de la alta capacidad embolígena, la afectación valvular suele tener una escasa repercusión hemodinámica, provocando en la mayoría de los casos una disfunción de grado ligero (5).
El diagnóstico de ETNB debe sospecharse ante la existencia de embolismos sistémicos múltiples en diferentes territorios. La ecocardiografía-Doppler transtorácica resulta una técnica útil para su evaluación, pero debido a su baja sensibilidad las vegetaciones de pequeño tamaño pueden pasar desapercibidas. Por ello, en caso de elevada sospecha clínica con ETT no concluyente, está indicada la realización de una ecocardiografía transesofágica (ETE). Sin embargo, es importante destacar que las lesiones valvulares de la ETNB resultan ecocardiográficamente indistinguibles de las obsevadas en la EI, por lo que es necesario establecer un diagnóstico diferencial con esta entidad (5). Este diagnóstico es especialmente dificultoso con los casos de EI con hemocultivos negativos, debiendo sospecharse un origen infeccioso hasta que el contexto clínico y el curso de la enfermedad demuestren lo contrario. En nuestra paciente, la ausencia de fiebre, los resultados negativos de los hemocultivos, tanto en medios convencionales como especiales y los resultados de las pruebas serológicas realizadas para excluir la presencia de otros microorganismos causantes de EI apoyaron el diagnóstico de ETNB. Finalmente, el estudio anatomo-patológico de la masa pulmonar mostró la existencia de una adenocarcinoma de pulmonar como enfermedad asociada a la ETNB.

La actitud terapeútica en estos pacientes debe dirigirse hacia el control de la enfermedad subyacente. La heparina intravenosa se utiliza para prevenir los fenómenos trombóticos (1) y el tratamiento anticoagulante a largo plazo está indicado en pacientes con síndrome antifosfolípido primario y en aquéllos con antecedente de episodios tromboembólicos (12). No obstante, no existen datos concluyentes que aconsejen un tratamiento definitivo. En los pacientes con insuficiencia valvular grave puede estar indicada la cirugía de recambio valvular si la situación clínica del paciente y el pronóstico de la enfermedad de base lo permiten.

\section{Bibliografía}

1. López JA, Ross RS, Fishbein MC, Siegel RJ. Nonbacterial thrombotic endocarditis: A review. Am Heart J 1987; 113: 773-84.

2. Rogers LR, Cho ES, Kempin S, Posner JB. Cerebral infarction from non bacterial thrombotic endocarditis. Am J Med 1987; 83: 746-56.

3. Brenner B, Blumenfeld Z, Markiewicz W, Reisner SA. Cardiac involvement in patients with primary antiphospholipid syndrome. J Am Coll Cardiol 1991; 18: 931-6.

4. Edoute Y, Haim N, Rinkevich D, Brenner B, Reisner SA. Cardiac valvular vegetations in cancer pactients: a prospective echocardiographic study of 200 patiens. Am J Med 1997; 102: 252-8.

5. Reisner SA, Brenner B, Haim N, Edoute Y, Markiewick W. Echocardiography in nonbacterial thrombotic endocarditis: from autopsy to clinical entity. Am Soc Echocardiogr 2000; 13: 876-81.

6. Kaul S, Fishbeim MC, Siegel RJ. Cardiac manifestations of acquierd inmunodeficiency syndrome: a 1991 update. Am Heart J 1991; 122: $535-44$
7. Truskinovsky AM, Hutchins GM. Association between nonbacterial thrombotic endocarditis and hypoxigenic pulmonary diseases. Virchows Arch 2001; 438: 357-61.

8. Rosen P, Armastrong D. Non-bacterial thrombotic endocarditis in patientes with malignant neoplastic disease. Am J. Med 1973; 54: 23-9.

9. Bedikian A, Valdivieso M, Luna M, Bodey GP. Non-bacterial thrombotic endocarditis in cancer patients: comparison of characteristics of patients with and without concomitant diseminated intravascular coagulation. Med Pediatr Oncol 1978; 4: 149-57.

10. Vilacosta I, San Román J.A, Sarriá C. Endocarditis trombótica no bacteriana. En: Vilacosta I, Sarriá C, San Román JA, editores. Endocarditis infecciosa. Barcelona: Prous Science, 2002; p. 339-47.

11. Newton HB. Neurologic complications of systemic cancer. Am Fam Physician 1999; 15; 59: 876-86.

12. Khamashta MA, Cuadrado MJ, Mujic F, Taub NA, Hunt BJ, Hughes G.R. The management of thrombosis in the antiphospholipid-antibody syndrome. N Engl J Med 1995; 332: 993-7. 